\title{
The role of gender in association between inhibition capacities and risky decision making
}

This article was published in the following Dove Press journal:

Psychology Research and Behavior Management

\author{
Semion Kertzman ${ }^{1,2}$ \\ Amichai Fluhr' \\ Michael Vainder ${ }^{3}$ \\ Abraham Weizman ${ }^{2,4,5}$ \\ Pinhas N Dannon ${ }^{1,2}$ \\ 'Department of Dual Disorders and \\ Rehabilitation, Beer-Yaakov-Ness \\ Ziona Mental Health Center, Ness \\ Ziona, Israel; ${ }^{2}$ Sackler Faculty of \\ Medicine, Tel Aviv University, Tel Aviv, \\ Israel; ' ${ }^{3}$ Environics Analytics, Toronto, \\ ON, Canada; ${ }^{4}$ Research Unit, Geha \\ Mental Health Center, Petach Tichvah, \\ Israel; ${ }^{5}$ Research Unit, Felsenstein \\ Medical Research Center, Petach \\ Tichvah, Israel
}

Correspondence: Pinhas N Dannon Department of Dual Disorders and Rehabilitation, Beer-Yaakov-Ness Ziona Mental Health Center, I Tarmag Street, Ness Ziona, Israel

Email Pinhas.danon@beerness.health.gov.il
Background: Research on the association between decision making and inhibition abilities has exhibited fundamental controversies. Some authors claim that inhibition abilities are an integral part of the decision-making process, whereas others suggest that the decisionmaking process does not operate in close association with inhibition abilities. Can gender explain variations in risky decisions via inhibition influences?

Purpose: The purpose of the present study was to explore the associations between response inhibition, reflection inhibition, interference inhibition, and decision-making processes in men and women. Methods: To this end, 46 women and 46 men were assessed by the Go/NoGo task, a measure of response inhibition, by the Matching Familiar Figure Test, a measure of reflection inhibition; and by the Stroop task, a measure of interference inhibition.

Results: No differences were detected in these measures between groups. The net score of the performance on the last section of the Iowa Gambling Task choices did not correlate with the inhibition measures in the two groups. We did not discover any significant main effects of gender on the association between these measures.

Conclusion: These findings do not support the hypothesis that risky decisions are due to impaired inhibitory control. Further studies are needed to identify the cognitive mechanisms involved in the tendency to make risky decisions.

Keywords: decision making, inhibition ability, gender differences, normal population

\section{Introduction}

One of the most crucial functions in everyday life is making choices. Decision making is the cognitive process resulting in the selection and production of a final choice among several alternative possibilities. ${ }^{1}$ Some aspects of decision making can be related to inhibition of irrelevant information, aimed to facilitate selection of the most appropriate behavior for achieving goals in a changing environment. ${ }^{2}$

This performance involves processes relevant to both learning to choose options with long-term outcomes and learning to avoid choices associated with negative consequences. Two approaches have been proposed to explain risky choices: 1) dysfunction of the decision-making process, which reflects impaired selection among several alternatives $^{3}$ and 2) inhibition deficits such as a tendency to respond rapidly to rewards without sufficient assessment of the potential consequences. ${ }^{4}$

The Iowa Gambling Task (IGT) is the most popular test designed to measure risktaking decisions. ${ }^{5}$ Some authors suggest an association between inhibition capacities and decision making. ${ }^{6,7}$ In contrast, others do not find this association. ${ }^{8-13}$ Although 
there is some overlap between disinhibition and risky decisions, ${ }^{14,15}$ they may represent separate independent entities. ${ }^{16}$

Efforts to identify and understand gender differences in risky decisions and inhibition capacities have a long history. Empirical research on gender and risk has focused on behavior in different arenas: health and physical safety; finance, including investment, gambling, and insurance; and strategic decision making in a professional work context. Many studies have shown that women are generally more risk averse ${ }^{17-20}$ than men. Furthermore, women not only are less risk-seeking ${ }^{21}$ but have different ways of making decisions. $^{22}$

Other authors have found that the association between gender and risky decision making is more complicated. For example, in an abstract lottery choice experiment, women were significantly more risk averse than men in the gain domain, but the opposite result was also found, with men being more risk averse than women in the loss domain. ${ }^{23}$ Men have been seen as more effective in the delayed rewards task, while females have outperformed males in the immediate rewards task. Females are more sensitive to reward frequency, but males are more sensitive to reward magnitude on intertemporal decisions made from experience. ${ }^{24}$ Men typically focus on the probability component of risks, whereas women focus on future consequences. If future consequences are losses, women on average perceive higher risks than do men. ${ }^{25}$ In a recent meta-analysis of 150 studies, males were found to express greater risk-taking decision than female participants ${ }^{26}$ according to the IGT measure. In contrast, men outperformed women on a version of the IGT. ${ }^{27}$ Thus, more in-depth research is needed to explore the gender-related differences in risky decision making. ${ }^{28}$

Several experiments, such as the dictator game, ${ }^{29}$ the threshold public game, ${ }^{30}$ the duopoly game, ${ }^{31}$ as well as loss domain gambling games, ${ }^{23}$ show no significant difference in performance between female and male groups. Males and females have been found to be equally efficacious at decision making in general. ${ }^{32}$

Inhibition is defined as the ability to withhold an action, namely, the ability to control a behavior that is relatively automatic. The tendency to act with little forethought has been linked to a proclivity for various risk behaviors. ${ }^{33}$ Recently, it is not clear if inhibition capacities influence the interaction between behavioral control and a risky decision differently in men as compared to that in women. Can gender explain variations in risky decisions via inhibition influences? Historically, there was greater pressure to inhibit emotional and sexual responses for prehistoric women than for men, resulting in an expectation of a higher degree of inhibition ability in females. ${ }^{34,35}$ Numerous studies have revealed that males are two to three times more susceptible to impairment in behavior control and more involved in a wide range of risky behaviors such as alcohol consumption, smoking, illicit drug use, or violence compared with females. ${ }^{36}$

In this study, we focused on the role of three inhibition capacities. The task selection was influenced by a desire to include tasks with different cognitive mechanisms. First, "response inhibition" refers to the ability to suppress dominant, automatic, or prepotent responses. The Go/NoGo task is the most widely used task to measure response inhibition and broad self-control functions associated with behavioral inhibition. ${ }^{37}$ Second, the Matching Familiar Figure Test (MFFT), a measure of reflection inhibition, refers to an individual's ability to wait before responding in a situation with several highly plausible alternatives, when only one of them is correct, and thereby creating a delay before action. ${ }^{38}$ Third, a capacity to protect a delay period from disruption by competing events and responses, namely, "resistance to distractor interference" involves avoiding interference with task-irrelevant information in the external environment. ${ }^{39} \mathrm{The}$ Stroop task is the most widely used means to measure interference inhibition. ${ }^{11,40}$ Impulsive behavior can be attributed to weaker interference control. ${ }^{41}$

Each of these three aspects of inhibitory mechanisms helps to control different delay periods during the decision process before the response. The selection of a dominant alternative for action is dependent on the effectiveness of an inhibitory regulatory process..$^{42}$ The assessment of each inhibition dimension is essential for the effort to identify specific mechanisms of risky decisions in different populations. Use of a single total inhibition score does not represent multiple control processes that do not correlate with each other. ${ }^{43}$

Although the literature demonstrates that women show a greater inhibition capacity in inhibition associated with a social aspect, ${ }^{44}$ in experimental situations in laboratories the results of studies on inhibition tasks have yielded mixed results. Sex differences in an inhibition control do exist, but the direction of these differences varies across specific capacities. In interruptive inhibition, women have been shown to exhibit poorer performance than males. ${ }^{45,46}$ In response inhibition, men have exhibited poorer performance than women. ${ }^{47,48}$ Other researchers, however, do not support this conclusion. ${ }^{49}$ Previously, it was found that response inhibition, as measured by decreasing numbers of commission errors, shows that girls are better able than boys to sustain the attention and vigilance necessary to consistently respond to the Go trials 
in continuous performance tasks. ${ }^{50}$ This capacity can help exhibit better response inhibition performance. During MFFT trials, sex-related differences in performance were absent. ${ }^{51}$ MacLeod (1991) showed that there were no sex differences in Stroop interference inhibition at any age. ${ }^{41}$ These features are consistent with the position that gender differences in inhibition are relatively domain specific. ${ }^{34}$ The inconsistent findings regarding men's and women's risky decision and inhibition capacities suggest that more studies are needed.

The aims of the current study are to examine the effect of gender on the relationship between inhibition capacities and decision making from the perspective of the strength of different facets of inhibition. We begin by assessing this issue in cognitive performance following the view that gender is more complicated than sex because it reflects psychological and social considerations as well as biological factors. ${ }^{52}$ Although previous findings have been mixed, our hypotheses arose from previous studies reporting female outperformance of men on tasks requiring inhibitory control and risky decisions.

We expected 1) that women would demonstrate better learning to avoid risky decision making during the IGT performance than men, 2) that inhibition capacities would be stronger in women than in men, particularly under conditions without time-pressure procedures. One potentially important point to mention here is that inhibition capacity was not narrowly defined in the current study. A broad pathway may exist from distinct inhibition capacities to make risky decisions, given that the response inhibition, reflection inhibition, and interference control facets independently accounted for variance in the relation between inhibition and risky decisions, and 3 ) that low inhibition capacities would be linked to worse performance on the IGT.

\section{Materials and methods Subjects}

Most participants were recruited by means of advertisements posted at universities in Israel (Tel Aviv University, the Hebrew University of Jerusalem, and Ben-Gurion University), through personal contacts and through social networks (eg, Facebook) inviting them to take part in a research project investigating decision-making styles. Participation in the study was voluntary and was unpaid. As compensation for participating in the study, participants received free consultation about their decision-making style based on the tests. Data collection was conducted during individual sessions with an explanation regarding the research aims and with the subject signing a consent form. The form indicated their willingness to participate in the research, which included a computerized neuropsychological examination and questions covering extensive background information. The duration of individual sessions was up to 1 hour. The sample size was estimated based on the difference in the IGT score between men and women. Assuming that the mean difference between the scores would be 11 with an SD of 21 in each of the groups, ${ }^{27}$ a significance level of 5\% (one-tailed), and a power of $80 \%$, a sample size of 46 participants in each group was sufficient to prove that the difference is statistically significant. We expect that comorbid neurological problems, alcohol use disorders, and drug dependence would result in additive effects on neurocognitive deficiencies. Thus, the exclusion criteria for the study were neurological disorders, alcohol or substance abuse/dependence (other than tobacco smoking), major psychiatric disorders, and treatment with any psychiatric medication. All participants completed a screening interview, which covered medical history, illicit drug use, and family and personal psychiatric history. All of the subjects were free of any psychopharmacological treatments.

\section{Decision-making measure Computerized animation variant of the lowa gambling test}

In the IGT, participants were exposed to four decks of cards (A, B, C , D) that were placed next to each other on a computer screen. They were informed that each deck was capable of awarding them virtual money. Participants were informed that they had 100 choices with the ultimate goal of being awarded the highest possible amount of virtual money. Participants were required to make continuous selections from decks of cards with different proportions of the amount of gains and losses. After having received this information, participants were instructed to choose one of the four decks for each trial by clicking the mouse on the respective deck to indicate their choice.

At this point, unknown to the participants, two disadvantageous decks have high initial "monetary" rewards but lead to negative overall outcomes (high money loss). Other decks have lower initial "money" rewards but also lower losses over time, making them advantageous in the long perspective of task performance. Over several trials, in which participants receive feedback on their gains and losses, participants learn to avoid the risky decks and to develop a preference for the safe card decks. ${ }^{5}$ We applied a modified computerized animation version of the IGT - Casino, which was described previously. ${ }^{10}$ One hundred card selections for each participant is divided into five blocks of 20 cards each. 
We calculate a net score for each block by subtracting the number of advantageous card selections from the number of disadvantageous card selections $([\mathrm{C}+\mathrm{D}]-[\mathrm{A}+\mathrm{B}])$ for each of the 20 cards. A score below zero signifies that subjects adopted a disadvantageous strategy overall (more card selections in decks A and B), while a score above zero implies a more advantageous deck preference (more card selections in decks $\mathrm{C}$ and $\mathrm{D}$ ). We used the net score of the performance on IGT section 5 (advantageous decks $[\mathrm{C}+\mathrm{D}]$ minus disadvantageous decks $[\mathrm{A}+\mathrm{B}])$.

\section{Inhibition measures The Go/NoGo task}

Response inhibition was assessed using a version of the Go/NoGo task, which has been described previously. ${ }^{53}$ Participants respond whenever a colored rectangle was visually presented on a computer screen. There are 120 red rectangles ("Go") and 30 black rectangles ("NoGo") in the task. Participants were required to make a button-press response to the Go stimuli and withhold that response to the NoGo stimuli. Stimuli are presented at a rate of one stimulus per 2,000 ms on the screen in random order for $100 \mathrm{~ms}$ each. A constant inter-stimulus interval was chosen to minimize any orienting response caused by the unpredictability of a stimulus display. The need for inhibition to NoGo stimuli is manipulated by requiring button presses to Go stimuli by frequency of Go stimuli, ensuring the Go response as pre-potent because of its high frequency. The test lasts for 5 minutes. Optimal performance on the Go/NoGo task involves minimizing both misses (not responding to a Go trial) and false alarms (responding to a NoGo trial).

\section{The Matching Familiar Figures Test}

We applied a computerized variant of the $\mathrm{MFFT}^{38}{ }^{38}$ as previously described. ${ }^{54}$ In our computerized version, participants were asked to select one of six alternative pictures that matched a standard picture, with all pictures being presented simultaneously. The participants continued to select until a match was found. This performance requires a visual search and hypothesis-testing skill in addition to reflexive inhibition. ${ }^{55}$ The MFFT contains one practice run followed by 12 experimental trials. There are two dependent measures: total number of errors and mean latency of the first response. The minimum number of errors was 0 , while the maximum was 60 .

\section{The Stroop task}

We used a manual key-press reverse variant of the Stroop task, as reported previously. ${ }^{56}$ In this assessment, participants were required to read the words and ignore the colors. Thus, the interference with word reading is caused by an incompatible, irrelevant ink color. ${ }^{41}$ Four color words (green, red, blue, or yellow) are presented individually in the center of the screen on a gray background printed in one of five colors: red, blue, green, yellow, or black. The word appears above two colored rectangles on each side. Subjects are instructed to press one of two keys. The color of the displayed word is always the same as the color of one of the rectangles, while the other rectangle carries the color of the meaning of the word. Presentation was time-unlimited: the stimuli change only if the examinee presses one of the designated keys. The task consists of 40 "neutral" trials in which the letters of the word are black; 40 "congruent" trials in which the word's meaning and the color of the letters correspond (eg, the word "RED" is displayed in red letters); and 40 "incongruent" trials in which the word's meaning does not correspond to the color of the letters (eg, the word "BLUE" is displayed in red letters). "Item-by-item" trials are pseudo-randomly ordered. Interference reaction time was calculated as the response time in the incongruent condition minus the response time in the congruent condition.

\section{Ethical aspects}

The study was fully approved by the local Beer-Yaakov/ Ness Ziona Mental Health Review Board committee and the Ministry of Health. All subjects provided a written informed consent after the experimental procedure and the nature of the neurocognitive tests were fully explained to them.

\section{Data analysis}

The data were analyzed using the statistical software package SAS v9.4 for Windows (SAS Institute). All analyses used two-tailed levels of significance. The parametric ( $t$-test) and nonparametric $\left(\chi^{2}\right)$ tests were performed to compare group differences in demographic and behavioral parameters. The variables age and education were categorized. The first age group contained participants of age $<30$ years and the second group included participants of age $\geq 30$ years. Education was blocked in three groups: below university, bachelor's degree, and postgraduate degree. The differences between groups in age and education were examined using a chi-squared test. Pearson's correlation coefficient was calculated to assess the linear relationships between inhibition measures: 1) the first response time (RT) and total number of errors in the MFFT, 2) the Go/NoGo mean of response time (as the sum of mean response time in the two blocks of the Go/NoGo task), and 3) Stroop interference response time (response time in the incongruent condition minus response time in the congru- 
ent condition) and IGT performance measure (sum of a net score for the 20 last selections: trials 80-100). Because the performance on the IGT had a strong learning component, ${ }^{57}$ we used only the last IGT selections, which were combined into a single measure.

Group comparisons were conducted using ANOVA, with IGT performance measure as the dependent variable. We used the three-way ANOVA, with the main effects being gender, age, and education and the interactions "gender-by-age" and "gender-by-education".

\section{Results}

The female participants were younger than the males (Table 1), and the chi-squared test demonstrated a significant age difference between the gender groups $\left(\chi^{2}=5.58, P=0.02\right)$. Even though male participants were slightly more educated than female participants (Table 1), the comparison of education did not demonstrate a significant difference between the gender groups $\left(\chi^{2}=2.06, P=0.36\right)$.

\section{Intergroup comparison of the impulsivity characteristics}

Both groups had impulsivity parameters in the normal range (Table 2). Univariate analysis did not find significant differences between the male and female groups of participants.

The net score of the performance on IGT section 5 did not correlate with the impulsivity parameters in either population group (Table 3 ). The results of the three-way ANOVA showed that there was no main effect of gender on the IGT parameter, $F(1,84)=0.02, P=0.88$. There were

Table I Population demographic characteristics

\begin{tabular}{|l|l|l|}
\hline Variable & Male (n=46) & Female (n=46) \\
\hline Age (years): $<30$ and $\geq 30$ & $23 / 23$ & $34 / 12$ \\
$\begin{array}{l}\text { Education: } \\
\text { (below bachelor's degree, } \\
\text { bachelor's degree, and above } \\
\text { bachelor's degree) }\end{array}$ & $1 \mathrm{I} / 6 / 24$ & $\mathrm{I} 2 / \mathrm{I} \mathrm{I} / 23$ \\
\hline
\end{tabular}

also no significant differences in the IGT parameter among the age and education groups, $F(1,84)=0.90, P=0.3461$ and $\mathrm{F}(2,84)=2.22, P=0.12$, respectively. Gender also did not interact with the age and education groups, $\mathrm{F}(1,84)=1.78$, $P=0.19$ and $\mathrm{F}(2,84)=1.91, P=0.16$, respectively.

\section{Discussion}

The current study examined the extent to which associations between three facets of inhibition - response, interference, and reflexive - and risky decisions varied as a function of gender. The current study did not find any significant difference in inhibition capacities and risky decisions between men and women (Table 2). The MFFT, the Go/NoGo, and the Stroop task measures were not associated with the IGT net score in either the men's or the women's group (Table 3 ). These results are concordant with previous studies that found that risky decision making was not influenced by inhibition capacities. ${ }^{8-13}$ The decision making and inhibition capacities represent separate cognitive mechanisms. Risky decisions are a result of a wrong solution for a dilemma among weighing the pros and cons of several alternatives. ${ }^{16}$ In contrast, inhibition control, which is most likely composed of several subtypes of mechanisms, is the ability to inhibit an overriding response in order to perform a less dominant one. ${ }^{58}$ In addition, our results are concordant with previous findings that found no differences between women and men in being risk-prone when high levels of uncertainty are introduced in a game. ${ }^{59}$

Table 3 Correlation between the net score of the last block of the IGT and the inhibition measures in male and female groups

\begin{tabular}{|l|l|l|l|}
\hline Test & Variable & Male & Female \\
\hline Go/NoGo & Mean RT & $-0.11(0.48)$ & $-0.10(0.53)$ \\
Go/NoGo & Errors of commission & $0.11(0.45)$ & $-0.05(0.77)$ \\
Stroop & Interference RT & $0.08(0.61)$ & $0.03(0.83)$ \\
MFFT & First RT & $0.01(0.94)$ & $-0.01(0.93)$ \\
MFFT & Errors & $-0.04(0.78)$ & $0.12(0.42)$ \\
\hline
\end{tabular}

Abbreviations: Go/NoGo, the GoNoGo task; MFFT, The Matching Familiar Figures Test; RT, response time; Stroop, the Stroop task.

Table 2 Between-group comparison of the inhibition and decision-making measures

\begin{tabular}{|l|l|l|l|l|l|l|l|}
\hline Task & Variable & \multicolumn{2}{l|}{ Male } & \multicolumn{2}{l|}{ Female } & \multicolumn{2}{l|}{ Statistics } \\
\cline { 2 - 8 } & & Mean & SD & Mean & SD & t-value & P-value \\
\hline Go/NoGo & Mean RT & 331.3 & 65.27 & 331.3 & 48.31 & 0.02 & 0.98 \\
Go/NoGo & Errors of commission & 1.50 & 1.6262 & 1.2609 & 1.5338 & 0.73 & 0.47 \\
Stroop & Interference (ms) & 113.3 & 144.30 & 129.4 & 94.84 & 0.63 & 0.53 \\
MFFT & First RT & 14.88 & 9.07 & 12.48 & 7.44 & 1.38 & 0.18 \\
MFFT & Errors & 3.83 & 3.31 & 3.56 & 3.11 & 0.40 & 0.69 \\
IGT & Net score last block & 4.39 & 11.97 & 6.04 & 11.40 & 0.68 & 0.50 \\
\hline
\end{tabular}

Abbreviations: Go/NoGo, the GoNoGo task; IGT, computerized animation variant of the lowa Gambling Test; MFFT, The Matching Familiar Figures Test; ms, milliseconds; RT, response time; Stroop, the Stroop task. 
We consider several explanations for the similar performance by gender. The degree of risk aversion shows significant cross-cultural differences. ${ }^{60,61}$ Israel provides an interesting context in which to examine gender-related differences for a number of reasons. For example, Jews appear to be more risk-prone than Catholics. ${ }^{62}$ Israel is a natural experiment field for an investigation of the contradiction between the "cushion hypothesis" and findings regarding risk aversion..$^{63}$ In contrast to traditional gender differences, both genders in the Israeli population are recruited by the military. Women drilling and training is similar to that of men, and they are assigned to a wide range of units ${ }^{64,65}$ because recently the traditional battlefield began to change due to the impact of high-tech innovations and looser definitions of battlefront and homefront. ${ }^{66}$ These changes make the masculine advantage less relevant and foster equality between men and women in the area of combat skills and, thus, may be equally needed to control their behavior. This experience in post-army civilian life can be presented in cognitive performance. Previously, it was found that gender role identification rather than sex differences significantly determine risky decisions. ${ }^{67}$

In addition, most of the participants in our study were master's degree university students recruited after intensive psychological and educational selection before admission to a university in Israel. Acquiring an academic education requires a certain level of self-discipline, long working hours, and many correct decisions to bring individuals of both genders closer to the desired goal. Is it possible that in a normative population the basic description of risk taking as deviant may be questionable? It is critical to keep in mind the positive side of risk-taking as it can be a great advantage in many instances. For example, risk-taking is a strategic component of effective management because managers need to take risks in order to achieve better outcomes. ${ }^{68}$ Possibly, this type of behavior is associated with a pattern of social rule breaking. ${ }^{69}$ Furthermore, the gap between men's and women's differences might have begun to close. ${ }^{70}$ Women are surpassing men in terms of educational outcomes,${ }^{71}$ but highly educated people tend to be more risk-prone than less educated people. ${ }^{72}$ Globalization and deregulation trends ${ }^{73}$ may be hastening women's emancipation. ${ }^{74}$ Also, the increased willingness to invest in long-duration professional degrees ${ }^{75}$ may be causing a reduction in the traditional differences between genders in our sample regarding risk-taking attitudes. Thus, genderrelated bias in the neuropsychological performance reflects the interaction of genes, hormones, and social learning on brain development throughout the lifespan, and sociocultural factors can complicate biological sex-related differences. ${ }^{76}$

\section{Conclusion}

In this study, we have explored whether gender-related differences contribute to an association between inhibition measures and risky decision making. To do so, we compared decisionmaking performance and performance on three inhibition tasks. The major contribution of the present study is that 1) there is no difference between men and women in risky decision and inhibition areas in an experimental situation and 2) the IGT performance and the three inhibition measures are tape the relative independent aspect (risky decisions versus inhibition control) of cognitive functioning in accordance with previous works..$^{8-13}$ This result supports the notion that there is no reason to assume that either gender is superior to the other in decision making. The absence of gender-related bias in risky decision and inhibition domains among highly educated Israeli participants may serve as a starting point for further research in this domain. To further study gender-related differences in decision making, we advise these studies be pursued in various other demographic groups of participants.

\section{Disclosure}

Dr Kertzman received personal fees from Animascan outside the work for this paper. The authors report no other conflicts of interest in this work.

\section{References}

1. Kable JW, Glimcher PW. The neurobiology of decision: consensus and controversy. Neuron. 2009;63(6):733-745.

2. Mansouri FA, Tanaka K, Buckley MJ. Conflict-induced behavioural adjustment: a clue to the executive functions of the prefrontal cortex. Nat Rev Neurosci. 2009;10(2):141-152.

3. Clark L, Bechara A, Damasio H, Aitken MR, Sahakian BJ, Robbins TW. Differential effects of insular and ventromedial prefrontal cortex lesions on risky decision-making. Brain. 2008;131(Pt 5):1311-1322.

4. Bari A, Robbins TW. Inhibition and impulsivity: behavioral and neural basis of response control. Prog Neurobiol. 2013;108:44-79.

5. Bechara A. Iowa gambling task professional manual. Lutz: Psychological Assessment Resources; 2007.

6. Cassotti M, Moutier S. How to explain receptivity to conjunction-fallacy inhibition training: evidence from the Iowa gambling task. Brain Cogn. 2010;72(3):378-384

7. Noël X, Bechara A, Dan B, Hanak C, Verbanck P. Response inhibition deficit is involved in poor decision making under risk in nonamnesic individuals with alcoholism. Neuropsychology. 2007;21(6): 778-786.

8. Buelow MT, Suhr JA. Construct validity of the Iowa Gambling Task. Neuropsychol Rev. 2009;19(1):102-114.

9. Fernie G, Cole JC, Goudie AJ, Field M. Risk-taking but not response inhibition or delay discounting predict alcohol consumption in social drinkers. Drug Alcohol Depend. 2010;112(1-2):54-61.

10. Kertzman S, Lidogoster H, Aizer A, Kotler M, Dannon PN. Risk-taking decisions in pathological gamblers is not a result of their impaired inhibition ability. Psychiatry Res. 2011;188(1):71-77.

11. Morris TM, Hudson JL, Dodd HF. Risk-taking and inhibitory control in behaviourally inhibited and disinhibited preschool children. Pers Individ Dif. 2014;71(5):113-117. 
12. Sun DL, Chen ZJ, Ma N, Zhang XC, Fu XM, Zhang DR. Decisionmaking and prepotent response inhibition functions in excessive internet users. CNS Spectr. 2009;14(2):75-81.

13. Toplak ME, Sorge GB, Benoit A, West RF, Stanovich KE. Decisionmaking and cognitive abilities: A review of associations between Iowa Gambling Task performance, executive functions, and intelligence. Clin Psychol Rev. 2010;30(5):562-581.

14. Busemeyer JR, Stout JC. A contribution of cognitive decision models to clinical assessment: decomposing performance on the Bechara gambling task. Psychol Assess. 2002;14(3):253-262.

15. Miller E, Joseph S, Tudway J. Assessing the component structure of four self-report measures of impulsivity. Pers Individ Dif. 2004;37(2):349-358

16. Bechara A. Risky business: emotion, decision-making, and addiction. J Gambl Stud. 2003;19(1):23-51.

17. Brooks R, Faff R, Mulino D, Scheelings R. Deal or no deal, that is the question: The impact of increasing stakes and framing effects on decision-making under risk. Int Rev Finance. 2009;9(1-2):27-50.

18. Eckel CC, Grossman PJ. Differences in the economic decisions of men and women: experimental evidence. In: Plott CR, Smith VL, editors. Handbook of Experimental Economics Results. Amsterdam: North Holland; 2008:509-519.

19. Jung $S$, Choe C, Oaxaca RL. Gender wage gaps and risky vs. secure employment: An experimental analysis. Labour Econ. 2018;52(10): 112-121.

20. Palvia A, Vähämaa E, Vähämaa S. Are Female CEOs and Chairwomen More Conservative and Risk Averse? Evidence from the Banking Industry During the Financial Crisis. J Business Ethics. 2015;131(3):577-594.

21. Croson R, Gneezy U. Gender Differences in Preferences. J Econ Lit. 2009;47(2):448-474.

22. Powell M, Ansic D. Gender differences in risk behaviour in financial decision-making: An experimental analysis. J Econ Psychol. 1997;18(6):605-628.

23. Schubert R, Brown M, Gysler M, Brachinger HW. Financial Decision-Making: Are Women Really More Risk Averse? Am Econ Rev 1999;89(2):381-385.

24. Cornwall AC, Byrne KA, Worthy DA. Gender differences in preference for reward frequency versus reward magnitude in decision-making under uncertainty. Pers Individ Dif. 2018;135(1):40-44.

25. Schubert R. Analyzing and managing risks - on the importance of gender differences in risk attitudes. Managerial Finance. 2006;32(9):706-715

26. Byrnes JP, Miller DC, Schafer WD. Gender differences in risk taking: A meta-analysis. Psychol Bull. 1999;125(3):367-383.

27. Reavis R, Overman WH. Adult sex differences on a decision-making task previously shown to depend on the orbital prefrontal cortex. Behav Neurosci. 2001;115(1):196-206.

28. Maxfield S, Shapiro M, Gupta V, Hass S. Gender and risk: women, risk taking and risk aversion. Gen Manag Int J. 2010;25(7):586-604.

29. Bolton GE, Katok E. An experimental test for gender differences in beneficent behavior. Econ Lett. 1995;48(3-4):287-292.

30. Cadsby CB, Maynes E. Gender and free riding in a threshold public goods game: Experimental evidence. J Econ Behav Organ. 1998;34(4):603-620.

31. Mason CF, Phillips OR, Redington DB. The role of gender in a noncooperative game. J Econ Behav Organ. 1991;15(2):215-235.

32. Sila V, Gonzalez A, Hagendorff J. Women on board: Does boardroom gender diversity affect firm risk? Journal of Corporate Finance. 2016;36:26-53C.

33. Verdejo-García A, Lawrence AJ, Clark L. Impulsivity as a vulnerability marker for substance-use disorders: review of findings from high-risk research, problem gamblers and genetic association studies. Neurosci Biobehav Rev. 2008;32(4):777-810.

34. Bjorklund DF, Kipp K. Parental investment theory and gender differences in the evolution of inhibition mechanisms. Psychol Bull. 1996;120(2):163-188.

35. Hosseini-Kamkar N, Morton JB. Sex differences in self-regulation: an evolutionary perspective. Front Neurosci. 2014;8:233.
36. Substance Abuse and Mental Health Services Administration, Results from the 2013 National Survey on Drug Use and Health: Summary of National Findings, NSDUH Series H-48, HHS Publication No. (SMA) 14-4863. Rockville, MD: Substance Abuse and Mental Health Services Administration, 2014.

37. Nigg JT. On inhibition/disinhibition in developmental psychopathology: views from cognitive and personality psychology and a working inhibition taxonomy. Psychol Bull. 2000;126(2):220-246.

38. Kagan J, Rosman BL, Day D, Albert J, Phillips W. Information processing in the child: Significance of analytic and reflective attitudes. Psychol Monogr. 1964;78(1):1-37.

39. Logan GD. Attention and automaticity in Stroop and priming tasks: theory and data. Cogn Psychol. 1980;12(4):523-553.

40. Cheng ASK, Lee HC. Risk-taking behavior and response inhibition of commuter motorcyclists with different levels of impulsivity. Transp Res Part F Traffic Psychol Behav. 2012;15(5):535-543.

41. Macleod CM. Half a century of research on the Stroop effect: an integrative review. Psychol Bull. 1991;109(2):163-203.

42. Moeller FG, Barratt ES, Dougherty DM, Schmitz JM, Swann AC. Psychiatric aspects of impulsivity. Am J Psychiatry. 2001;158(11):1783-1793.

43. Dougherty DM, Mathias CW, Marsh DM, Jagar AA. Laboratory behavioral measures of impulsivity. Behav Res Methods. 2005;37(1):82-90.

44. Imhoff R, Schmidt AF. Sexual disinhibition under sexual arousal: evidence for domain specificity in men and women. Arch Sex Behav. 2014;43(6):1123-1136.

45. Colzato LS, Hertsig G, van den Wildenberg WP, Hommel B. Estrogen modulates inhibitory control in healthy human females: evidence from the stop-signal paradigm. Neuroscience. 2010;167(3):709-715.

46. Morgan JE, Gray NS, Snowden RJ. The relationship between psychopathy and impulsivity: A multi-impulsivity measurement approach. Pers Individ Dif. 2011;51(4):429-434.

47. Saunders B, Farag N, Vincent AS, et al. Impulsive errors on a Go/NoGo reaction time task: disinhibitory traits in relation to a family history of alcoholism. Alcohol Clin Exp Res. 2008;32(5):888-894.

48. Hasson R, Fine JG. Gender differences among children with ADHD on continuous performance tests: a meta-analytic review. J Atten Disord. 2012;16(3):190-198.

49. Sjoberg EA, Cole GG. Sex Differences on the Go/No-Go Test of Inhibition. Arch Sex Behav. 2018;47(2):537-542.

50. Conners CK, Epstein JN, Angold A, Klaric J. Continuous performance test performance in a normative epidemiological sample. J Abnorm Child Psychol. 2003;31(5):555-562.

51. Haghighi M, Ghanavati M, Rahimi A. The Role of Gender Differences in the Cognitive Style of Impulsivity/Reflectivity and EFL Success. Procedia Soc Behav Sci. 2015;192:467-474.

52. Meier-Pesti K, Goetze E. Masculinity and femininity as predictors of financial risk-taking: evidence from a priming study on gender salience. In: Ekstrom KM, Brembeck H, editors. E - European Advances in Consumer Research. Goteborg, Sweden: Association for Consumer Research; 2005:45-46.

53. Kertzman S, Lowengrub K, Aizer A, Vainder M, Kotler M, Dannon PN. Go-No-Go performance in pathological gamblers. Psychiatry Res. 2008;161(1):1-10.

54. Kertzman S, Vainder M, Vishne T, Aizer A, Kotler M, Dannon PN. Speed-accuracy tradeoff in decision-making performance among pathological gamblers. Eur Addict Res. 2010;16(1):23-30.

55. Crone EA, Vendel I, van der Molen MW. Decision-making in disinhibited adolescents and adults: insensitivity to future consequences or driven by immediate reward? Pers Individ Dif. 2003;35(7):1625-1641.

56. Kertzman S, Lowengrub K, Aizer A, Nahum ZB, Kotler M, Dannon PN. Stroop performance in pathological gamblers. Psychiatry Res. 2006;142(1):1-10.

57. Franken IH, van Strien JW, Nijs I, Muris P. Impulsivity is associated with behavioral decision-making deficits. Psychiatry Res 2008;158(2):155-163.

58. Rothbart MK, Ellis LK, Rueda MR, Posner MI. Developing mechanisms of temperamental effortful control. J Pers. 2003;71(6):1113-1144. 
59. Borghans L, Golsteyn BHH, Heckman JJ, Meijers H. Gender differences in risk aversion and ambiguity aversion. J Eur Econ Assoc. 2009;7(2-3):649-658.

60. Booth AL, Nolen P. Gender differences in risk behaviour: does nurture matter? Econ J. 2012;122(558):F56-F78.

61. Rieger MO, Wang M, Hens T. Risk Preferences Around the World. Manage Sci. 2015;61(3):637-648.

62. Benjamin DJ, Choi JJ, Fisher G. Religious identity and economic behavior. NBER Working Paper No 15925; 2010.

63. Tavor T, Garyn-Tal S. Further examination of the demographic and social factors affecting risk aversion. Finan Market Portfolio Manag. 2016;30(1):95-110.

64. Sasson-Levy O. Feminism and Military Gender Practices: Israeli Women Soldiers in "Masculine" Roles. Sociol Inq. 2003;73(3):440-465.

65. Silva JM. A new generation of women? How female ROTC cadets negotiate the tension between masculine military culture and traditional femininity. Social Forces. 2008;87(2):937-960.

66. Haltiner K, Kümmel G. The hybrid soldier: Identity changes in the military. In: Kümmel G, Caforio G, Dandeker C, editors. Armed Forces, Soldiers and Civil-Military Relations. Wiesbaden: VS Verlag; 2009: 75-82.

67. Radecki CM, Jaccard J. Gender-Role Differences in Decision-Making Orientations and Decision-Making Skills. J Appl Soc Psychol. 1996;26(1):76-94
68. Hoskisson RE, Chirico F, Zyung J, Gambeta E. Managerial risk taking: A multi-theoretical review and future research agenda. J Manag. 2017;43(1):137-169.

69. Kahari WI, Mildred K, Micheal N. The contribution of work characteristics and risk propensity in explaining pro-social rule breaking among teachers in Wakiso District, Uganda. SA J Indust Psychol. 2017;43:a1368.

70. van Arensbergen P, van der Weijden I, van den Besselaar P. Gender differences in scientific productivity: a persisting phenomenon? Scientometrics. 2012;93(3):857-868.

71. Buchmann C, Diprete TA, Mcdaniel A. Gender Inequalities in Education. Annu Rev Sociol. 2008;34(1):319-337.

72. Dohmen T, Falk A, Huffman D, Sunde U. Are risk aversion and impatience related to cognitive ability? Am Econ Rev. 2010;100(3):1238-1260.

73. Black SE, Brainerd E. The impact of globalization on gender discrimination. ILR Review. 2004;57(4):540-559.

74. Guiso L, Rustichini A. What drives women out of management? The joint role of testosterone and culture. Eur Econ Rev. 2017; CEPR Discussion Paper No DP8204.

75. Blau FD, Kahn LM. The U.S. Gender Pay Gap in the 1990S: Slowing Convergence. ILR Review. 2006;60(1):45-66.

76. Meyers-Levy J, Loken B. Revisiting gender differences: What we know and what lies ahead. J Consum Psychol. 2015;25(1):129-149.
Psychology Research and Behavior Management

\section{Publish your work in this journal}

Psychology Research and Behavior Management is an international, peerreviewed, open access journal focusing on the science of psychology and its application in behavior management to develop improved outcomes in the clinical, educational, sports and business arenas. Specific topics covered in the journal include: Neuroscience, memory and decision making; Behavior
Dovepress

modification and management; Clinical applications; Business and sports performance management; Social and developmental studies; Animal studies. The manuscript management system is completely online and includes a very quick and fair peer-review system, which is all easy to use. Visit http://www. dovepress.com/testimonials.php to read real quotes from published authors. 